\title{
Cooperativas y prácticas laborales en México
}

\section{Cooperatives and labor practices in Mexico}

\author{
Graciela Lara Gómez**
}

Recibido: 13 de marzo de 2019

Revisado: 22 de mayo de 2019

Aprobado: 10 de junio de 2019

* Cómo citar este artículo: Lara Gómez, G. (2019). Cooperativas y prácticas laborales en México. Revista CIFE: Lecturas de Economía Social, 21(35), 81-104. DOI: https://doi.org/10.15332/22484914.5371

** Profesora-investigadora de la Universidad Autónoma de Querétaro, México. Miembro del Sistema Nacional de Investigadores nivel 1 (Conacyt). Doctora en Estudios Organizacionales por la Universidad Autónoma Metropolitana y doctorante en Economía Social de la Universidad de Valencia. Correo electrónico: glara@uaq.mx 


\title{
Resumen
}

El objetivo del artículo fue identificar las consecuencias que derivan de las prácticas de trabajo indebidas que se efectúan a través de cooperativas de producción en México. El estudio se centró en la subcontratación como una estrategia ampliamente difundida entre el sector empresarial, para reducir cargas financieras e incrementar sus utilidades, e inició con la revisión teórica desde las perspectivas económica y legal, que incluyó el análisis de las normas legales, criterios administrativos e información económica. Finalmente, se establecen las consecuencias referidas a los contextos tributario y laboral, así como en relación con los avances que se han logrado para evitar tales prácticas.

Palabras clave: cooperativas, trabajo, prácticas, regulación.

Clasificación JEL:J54, P13, M55, M51.

\begin{abstract}
The aim of the article was to identify the consequences that derive from improper work practices that are carried out through production cooperatives in Mexico. So the study focused on outsourcing as a widely spread strategy among the business sector, to reduce financial burdens and increase profits. So it began with the theoretical review from the economic and legal perspectives, which included the analysis of legal norms, administrative criteria and economic information. To then establish the consequences related to tax and labor contexts, as well as the progress that has been achieved to avoid such practices.
\end{abstract}

Keywords: cooperatives, work, practices, regulations.

Classification JEL: J54, P13, M55, M51. 


\section{Introducción}

Diversas y novedosas formas organizacionales se han gestado en torno a la economía social y solidaria, con el propósito de contribuir a la mejora en las condiciones de vida de las personas que comparten necesidades e intereses comunes. Una de esas organizaciones es la sociedad cooperativa, que es la forma jurídica más reconocida de esta tendencia económica.

Las cooperativas son organizaciones sociales orientadas a la solidaridad y no al capital, por lo que el ser humano que vive en comunidad es su razón de ser. Tales sociedades representan una opción factible para ayudar al avance empresarial colectivo, permitiendo que sus integrantes tomen el mando de su propio desarrollo. No obstante, se ha identificado en el contexto mundial que tales formas organizativas se han utilizado como un medio para promover la precarización laboral, por lo que se les ha llamado "falsas cooperativas" (García, 2018).

No obstante lo mencionado, debe advertirse que no son las únicas figuras jurídicas con las que ha crecido la precarización laboral, sino que además han surgido otras formas en el marco de la informalidad, que requieren de pronta atención - como la contratación de migrantes - (Roy \& Verdun) o de los trabajadores independientes, a los que Merker (2019) concibe como "invisibles", pues no tienen acceso a la mínima protección social. Por consiguiente, es importante señalar que este es un problema presente en los mercados laborales y que tiene una persistencia regional en América Latina y en otros contextos geográficos. Tal situación se ha agudizado, entre otras razones, por la crisis financiera de 2008, que tuvo repercusiones de alcance mundial y que resultó en una reducción en la demanda laboral de las empresas que mantuvieron relaciones crediticias con bancos afectados (Popov \& Rocholl, 2018).

Las "falsas cooperativas" se crean con la intencionalidad de sus administradores de simular la constitución de una sociedad cooperativa, utilizando indebidamente sus denominaciones y evadiendo obligaciones tributarias y laborales. Con la problemática presentada, se formuló la pregunta de investigación ¿cuáles son las consecuencias que derivan de las prácticas de trabajo indebidas que se llevan a cabo a través de cooperativas de producción de servicios en México?

Se indagó, entonces, sobre la problemática, características y consecuencias, analizando los avances legislativos en materia laboral, tributaria y el posicionamiento de la Corte. Por tanto, en un primer momento se llevó a cabo una aproximación teórica a la economía social y solidaria, y aspectos laborales, para en seguida identificar las prácticas de subcontratación — también llamada tercerización u outsourcing - en las cooperativas de producción de servicios en México. El diseño metodológico se basó en el método exegético, atendiendo a la revisión doctrinaria del tema, a las normas en el tema 
cooperativo y el análisis de las resoluciones de la Suprema Corte de Justicia de la Nación (SCJN), para dilucidar los argumentos que son presentados por los jueces en la resolución de casos vinculados con tales prácticas indebidas.

Finalmente, se advirtió que la subcontratación a través de las cooperativas ha persistido a través del tiempo y se han enquistado en las prácticas empresariales y laborales de la sociedad mexicana, por lo que aún falta mucho por hacer para fomentar prácticas empresariales éticas.

\section{Perspectiva teórica}

Para el desarrollo teórico se inició con la exploración en torno a la economía social y solidaria, subrayando algunas prácticas laborales que persisten entre organizaciones propias de esta tendencia económica. Asimismo, se incluye el posicionamiento de la Organización Internacional del Trabajo (OIT) sobre la precarización laboral y se muestra la opinión de expertos en el tema.

\subsection{La economía social y solidaria y el trabajo}

En las últimas décadas han emergido nuevas formas organizacionales con características propias, que se alejan de la visión propia de las empresas de capitales y que coadyuvan a la visión económico-social de las empresas sociales. Tales organizaciones tienen su origen en las que surgieron a raíz de las ideas del socialismo utópico y que pueden ubicarse en el siglo xix (Pérez de Mendiguren, Etxezarreta, \& Guridi, 2008), por lo que representa la evolución de otras iniciativas empresariales, que constituyen una incipiente generación de formas organizativas que, según Stiglitz (2015), demandan la participación articulada de los mercados, el Estado, los individuos y las comunidades.

Felber (2012) propone crear un modelo alternativo al sistema dominante que contenga valores muy similares a los que ya se habían propuesto desde la Economía Social como los valores y principios cooperativos que promueve la ACI (2016) - y luego fortalecidas en la economía social y solidaria - del último cuarto del siglo xx-, urgiendo a modificar la visión economicista y sustituirla con la filosofía de la cooperación, pues, considerando lo afirmado por Tirole (2017), el mercado no es equitativo y no persigue el bien común.

La economía social y solidaria tiene su anclaje en la tradición de la economía social y el cooperativismo (Abad \& Abad, 2014), pero con un importante elemento político, que incluye la participación de naciones y organismos no gubernamentales que han insistido 
en la incorporación de prácticas laborales éticas en las políticas públicas de los países. Es por ello que Fonteneau et al. (2011), a través de la Organización Internacional del Trabajo, han subrayado la diversidad de formas organizacionales que se incrustan en la tendencia mencionada y que abarcan desde las cooperativas, sociedades mutuales, asociaciones, organizaciones comunitarias, empresas sociales y algunas fundaciones. Todas ellas sostienen su actuar en la solidaridad, participación, innovación, adhesión voluntaria y propiedad colectiva.

En este sentido, la OIT ha pugnado por erradicar las prácticas de trabajo precario y transitar a lo que se ha denominado trabajo decente. En tal organismo se considera que la problemática se ha agravado a partir de la crisis financiera de 2007, pues las fuentes de empleo en los sectores públicos han disminuido, además de que se han recortado los salarios y millones de trabajadores tienen empleos precarios, temporales y eventuales (OIT, 2012).

Es por ello que Coraggio (2007) considera inaplazable que se incorpore a la economía dominante un subsistema al que se denominaría economía del trabajo, cuya operatividad modifique la situación de vida que prevalece entre los excluidos y los marginados, pero que además incremente el desarrollo en su más amplio espectro social. Consecuentemente, se contempla una versión alejada del trabajo mercantil (asalariado-capitalista), que implica el trabajo de reproducción, es decir, producción de bienes y servicios destinados al autoconsumo, el trabajo para la producción solidaria de bienes y servicios para el consumo en común y el trabajo de formación y capacitación.

Con esta lógica, las formas laborales que se reconocen en las organizaciones de la economía social y solidaria van de la creación de cooperativas hasta otras formas de reciprocidad, como los que se practican a través de los bancos de tiempo, donde se permiten intercambios de servicios, es decir, tiempo y destreza que no tienen un valor monetario, generando de esta manera otro tipo de mercado (Martellini, 2014). Todo ello es coincidente con lo propuesto con Felber (2012), quien pugna por un modelo alternativo que destaque la esencia social y económica en las nuevas y en las tradicionales organizaciones que fomentan la asociación y el trabajo de los socios.

Algunos datos relevantes de la Alianza Cooperativa Internacional (ACI) dicen que las cooperativas generan más de 100 millones de empleos en el mundo, lo que representa un $20 \%$ de lo que ofertan las firmas multinacionales (ACI, 2016). Igualmente, la OIT (2015) coincide en señalar que las cooperativas emplean a casi 100 millones de personas a nivel mundial y que contribuyen asegurando la subsistencia de casi la mitad de la población mundial.

Tales datos muestran la relevancia de las cooperativas en el contexto internacional, por lo que uno de los elementos destacables es el autoempleo, que representa uno de los ejes 
que sostiene la razón de ser de la economía social y solidaria. Para el caso mexicano, la actividad laboral con las características de tal tendencia económica se ha regulado a través de las cooperativas de producción de servicios, pero su noble finalidad ha sido tergiversada por las simulaciones de que han sido objeto, mediante la creación de cooperativas para llevar acabo precarización laboral y evasión tributaria.

Por lo anterior, se afirma que las organizaciones de la economía social y solidaria promueven el trabajo y son importantes en el contexto mundial por la oferta de trabajo que promueven, ya que se ha demostrado una correlación positiva entre empresas propiedad de los empleados y su productividad, además de que se generan mayores retornos financieros y empleos estables (OIT, 2015).

No obstante sus bondades, las cooperativas se han visto involucradas en prácticas predatorias que inhiben la existencia del trabajo de calidad, fomentando el trabajo precario, tal como se verá en el siguiente apartado.

\subsection{Prácticas laborales y cooperativas}

Desde la aspiración de construir una nueva economía (Felber, 2012), es dable traer a la discusión lo propuesto por Coraggio (2007), quien dice que hace falta una economía del trabajo, pero esto no deja de ser una aspiración legítima que se genera a la luz del deterioro de la calidad del trabajo y de las legislaciones nacionales. La economía del trabajo propuesta por Coraggio advierte que no puede sostenerse exclusivamente con pequeñas acciones voluntarias, sino que se requiere la reestructura de diversos sistemas públicos como el que corresponde a temas de educación y salud, los que deben ser puntales para la mejora en la calidad de vida y las capacidades productivas. En efecto, se requiere de la participación de la sociedad y del Estado, para sostener la propuesta y modificar la perspectiva actual de la relación laboral.

La OIT (2012) propone introducir políticas económicas y sociales para combatir el trabajo precario, pero también promover la normatividad existente e incrementar la reglamentación. En este sentido, el trabajo precario desde la visión de la Federación Europea de Metalúrgicos (FEM) se define como "un término que se utiliza para describir un empleo no estándar, de salario bajo, inseguro, que no ofrece protección ni permite al trabajador dar sustento a su familia" (p. 33).

Las características que pueden encontrarse en el trabajo precario son percibidas a través de dos supuestos: los arreglos contractuales y las condiciones laborales. En los arreglos contractuales, se presupone la existencia de un contrato de corta duración, con relaciones de trabajo que no identifican claramente al empleador y que no se proporciona seguridad social. Las condiciones laborales, en cambio, están representadas por 
salarios bajos, nula protección al momento del despido o la imposibilidad de ejercer derechos, así como la carencia de acceso a la seguridad social. A este respecto, la OIT (2012) dice que tanto los arreglos contractuales como las condiciones laborales son los elementos que prevalecen en las diferentes modalidades de trabajo precario, pero formalizando la relación laboral mediante ordenamientos jurídicos, lo que tiene un efecto nocivo que resulta en contrataciones falsas, trianguladas o encubiertas (tabla 1).

Tabla 1. Contratos y condiciones del trabajo precario

\begin{tabular}{|c|c|}
\hline Arreglos contractuales & Condiciones precarias \\
\hline $\begin{array}{l}\text { Limitada duración del contrato (plazo fijo, corto } \\
\text { plazo, temporal, estacional, trabajo a jornal y em- } \\
\text { pleo ocasional). }\end{array}$ & Salario bajo. \\
\hline $\begin{array}{l}\text { Naturaleza de la relación de trabajo (relaciones de } \\
\text { trabajo triangulares y encubiertas, falso autónomo, } \\
\text { contratos de agencias o subcontratistas). }\end{array}$ & Escasa protección frente al despido. \\
\hline $\begin{array}{l}\text { Contrataciones que no proporcionan la seguridad } \\
\text { social obligatoria, contemplada en normas jurídicas. }\end{array}$ & $\begin{array}{l}\text { Falta de acceso a la protección social y a los } \\
\text { beneficios que se suelen asociar con un empleo } \\
\text { estándar de tiempo completo. }\end{array}$ \\
\hline $\begin{array}{l}\text { Acuerdos ilegales previos a la contratación que nu- } \\
\text { lifican el acceso a la intervención de las autoridades } \\
\text { laborales y judiciales. }\end{array}$ & $\begin{array}{l}\text { Posibilidad limitada o nula de los trabajadores de } \\
\text { ejercer sus derechos en su trabajo, por firmas an- } \\
\text { ticipadas de renuncia laboral o por la simulación } \\
\text { de ser socio de cooperativas. }\end{array}$ \\
\hline
\end{tabular}

Fuente: elaboración propia con base en OIT (2012).

Como lo ha afirmado Tirole (2017), la equidad no es fácilmente detectable en una economía de mercado, por lo que actualmente se prioriza la obtención de rendimientos en detrimento de las personas. Por su parte, De Lara (2017) concuerda con la posición de la OIT (2012), indicando que la precarización laboral implica bajos salarios, nulo acceso a prestaciones sociales y a servicios de salud y vivienda, contratación temporal que impide generar antigüedad, por lo que no se podrá acceder a una pensión y, en general, inseguridad en el empleo.

El Consejo Nacional de Evaluación de la Política de Desarrollo Social (Coneval, 2018) recupera los aspectos centrales del trabajo digno, que se encuentra contenido en la Ley Federal del Trabajo (2018) en México, distinguiendo el respeto a la dignidad humana, fuera de toda discriminación y garantizando el acceso a la seguridad social, la percepción de un salario remunerador y el respeto a los derechos de los trabajadores.

El Coneval (2018) destaca que son evidentes diferentes disfunciones en cuanto a la formalidad de la relación laboral y las condiciones que deben preservarse, pues de 2005 a 2105 la población en edad de laborar creció 20.3\%, pero el empleo informal se incrementó 
y al mismo tiempo se generó una caída salarial, lo que ha conducido a una extendida precariedad, que limita la formalización de los contratos de trabajo y que se caracteriza por salarios muy bajos.

De manera que se ha percibido el acrecentamiento de prácticas laborales indebidas que disminuyen los costos y elevan las utilidades en las empresas a costa de la precarización laboral y el consecuente deterioro de la calidad de vida del trabajador y sus familias. De Lara (2017) dice que la coyuntura política de fines del siglo xx se ha irradiado en diferentes latitudes para permitir la libertad y flexibilidad en los contratos laborales, lo que ha derivado en el fin del derecho del trabajo.

En correspondencia, diversos autores han evidenciado la problemática que se ha originado del uso inadecuado de las cooperativas. Por ejemplo, García (2018) pone en la discusión desde una perspectiva jurídica el rol de las falsas cooperativas, señalando que se utiliza la legislación para explotar en beneficio propio a las organizaciones dedicadas al trabajo asociado. Por su parte, Freítas (2001) plantea la problemática de las cooperativas de trabajo en Brasil, indicando la intensidad con que se lleva a cabo la tercerización o subcontratación en el servicio público. Por su parte, Neffa (2010) reafirma la problemática por la que transitan las cooperativas de Brasil, pero también en Argentina, como resultado del crecimiento industrial de países que son altamente exportadores, los que se han visto forzados a ofrecer bienes novedosos, de calidad y a bajo costo, lo que ha presionado la estructura de costos, particularmente en lo referido a los costos salariales directos e indirectos.

Lo anterior no es ajeno a lo que ocurre en otros contextos geográficos, ya que en México se ha hecho un uso intensivo de figuras pertenecientes a la Economía Social y Solidaria - principalmente las cooperativas - , cuya característica vinculada con la flexibilización laboral (Neffa, 2010), así como la modificación del sistema de acumulación capitalista y la innovación tecnológica, han llevado al uso permanente de la subcontratación.

Pero el sector privado no es el único campo en el que se ha incrustado el tema de la subcontratación, sino también el gobierno en todos sus niveles. Debe mencionarse que, en principio, tal figura fue utilizada para la contratación de personal que desempeñara actividades no estratégicas. Por tanto, según Neffa (2010), la subcontratación de la siguiente manera:

El encargo o la entrega de una determinada actividad periférica, eventual o secundaria, de una empresa principal para ser realizada de manera autónoma, por una empresa subcontratada bajo su propia responsabilidad, especializada, cuya producción de bienes o de servicios no constituye el corazón de la empresa principal en cuanto a la generación del valor agregado y que no puede ser reconocida de hecho como proveedora de mano de obra. (Neffa, 2010, p. 51) 
Para los empresarios, este tipo de estrategias han sido financieramente exitosas, lo que ha llevado a que no solo se aplique para la contratación de actividades secundarias, sino también de actividades prioritarias y esenciales.

La subcontratación, entonces, ha dado lugar a la búsqueda de figuras jurídicas que sirvan para realizar actividades simuladas. Según García (2018), este fenómeno se ha difundido por todo el mundo a través del uso fraudulento de la legislación. Neffa (2010) coincide diciendo que dicha práctica ha significado una respuesta empresarial para no cubrir las cargas que representan las deudas laborales y para no enfrentar los costos de indemnización y otras inherentes a la terminación laboral. Todo ello ha traído como consecuencia que, en lugar de un emprendimiento fundamentado en el trabajo solidario, se opte por una alternativa en la lógica capitalista para disminuir costos, evadiendo al mismo tiempo las cargas tributarias que derivan de la contratación de personal.

Rojas (2004) indica que en Colombia se ha utilizado la figura de intermediación laboral y conjuntamente a las cooperativas de trabajo asociado como medio de suministrar personal, lo que es contrario a la disposición legal que prescribe que los responsables de la prestación de servicios serán los que tengan carácter de asociados. Igualmente, Lara y Rico (2007) reiteran que este escenario se replica en México, pues se ha utilizado a la cooperativa de producción de servicios como un mecanismo de contratación flexible que obliga a los trabajadores a entrar en una situación simulada, adoptando la calidad de socios sin serlo, lo que trae como resultado el menoscabo de sus derechos y condiciones laborales.

En torno a la apreciación jurídica que se ha dado en España a través de los argumentos de la Corte de 2001 y 2018, se ha expuesto que en las falsas cooperativas existe una "cesión ilegal de trabajadores" (García, 2018, p. 7), por lo que se ha afirmado que la relación del socio cooperativista con la propia cooperativa no es laboral.

Por su parte, De Lara (2017) dice que las reformas a la legislación laboral en América Latina y Europa han sido la respuesta a una malentendida promoción del empleo, que toma la reducción de costos implícitos en la contratación, lo que ha sido una pauta para orientar la actividad de los legisladores, por lo que se ha cambiado el rol de la protección del derecho laboral a una función promotora del empleo y la generación de utilidades en favor de las empresas. En consecuencia, Rojas (2004) afirma que la legislación no ha sido actualizada debidamente para enfrentar los nuevos escenarios que se viven en el contexto global. 


\section{Metodología}

La finalidad del artículo fue identificar las consecuencias que derivan de las prácticas de trabajo indebidas que se efectúan a través de cooperativas de producción en México. Para tal efecto, se realizó un recorrido teórico que implicó reconocer las prácticas laborales de subcontratación y los efectos que genera. Asimismo, se reconocieron las acciones que se han llevado a cabo desde los poderes ejecutivo y judicial, para inhibir las prácticas laborales indebidas realizadas a través de las cooperativas. De igual manera, para la investigación se atendió al método exegético, que se sustentó en la revisión doctrinaria, en el análisis de la normativa jurídica e información de la economía mexicana sobre el avance de la subcontratación.

Adicionalmente, para ilustrar la problemática y evolución de la subcontratación en México, se agrega un análisis del fenómeno, a partir de los datos oficiales disponibles, de los tres últimos censos económicos (Inegi, 2014, 2009, 2004).

\section{Desarrollo}

En el presente apartado se presenta el análisis de la situación que prevalece en México sobre las cooperativas y la simulación que a través de ellas se realiza para considerar a los trabajadores como socios y así evitar cargas financieras. Los beneficios indebidamente obtenidos se reflejan en beneficios empresariales, como la disminución de costos de producción y operativos, asociados con los salarios y las prestaciones que de dicha contraprestación se derivan, además de los relacionados con las aportaciones de seguridad social. Se discuten, además, las normatividades de autoridades administrativas, las reformas legislativas y las resoluciones de la scjN que se han dictado en torno de la función, características y esencia de las cooperativas.

\subsection{El trabajo y las cooperativas en México}

En los siguientes apartados se analizan los datos económicos sobre la subcontratación en México, para luego entrar al análisis de las normas jurídicas vigentes.

\subsubsection{El trabajo y la economía mexicana}

Según el Instituto Nacional de Estadística y Geografía (Inegi, 2018), en México la población total es de 124.5 millones de habitantes. La población económicamente activa (PEA) representa poco más de 54 millones, de ellos 52.19 millones se encuentra ocupada. El $50.8 \%$ de las personas que cuentan con empleo se concentran en las ciudades más 
grandes del país (de 100000 y más habitantes o capitales de entidad federativa). Un dato relevante de la Encuesta Nacional de Ocupación y Empleo (ENOE) es que el empleo informal suma 30.5 millones de personas.

Con datos de los Censos Económicos (Inegi, 2014, 2009, 2004), se ha detectado un incremento importante en la contratación de personal que no depende de la unidad económica en la que se reporta su fuente de trabajo. Esto indica que está proliferando el crecimiento de empresas que delegan las obligaciones laborales en otros entes jurídicos. Los datos derivados de los censos económicos muestran que entre 1998 y 2003 hubo un incremento de personal subcontratado del 40.1\% (Inegi, 2004), mientras que el periodo comprendido de 2003 a 2008 la tendencia se elevó al 95.2\% (Inegi, 2009), para el periodo de 2008-2013 hubo una tendencia a la baja, resultando que el incremento fue del $31 \%$. Este último escenario puede estar relacionado con las reformas a las leyes tributarias, para atenuar los efectos de evasión que se venían perpetrando a través de cooperativas de producción.

La tendencia desde 1998 a 2008 fue a la alza, por lo que la subcontratación se vio favorecida en el mercado laboral, ya para 2013 se refleja un incremento en menor proporción (figura 1).

Figura 1. Personal subcontratado (1998-2013)

\begin{tabular}{|cccc} 
Censo económico & Personal subcontratado & Diferencia absoluta & Tasa de crecimiento \% \\
\hline 1998 & 998,969 & sin dato & sin dato \\
\hline 2003 & $1,399,264$ & 400,295 & 40.1 \\
2008 & $2,732,056$ & $1,332,792$ & 95.2 \\
\hline 2013 & $3,578,247$ & 846,191 & 31.0 \\
\hline
\end{tabular}

Personal subcontratado

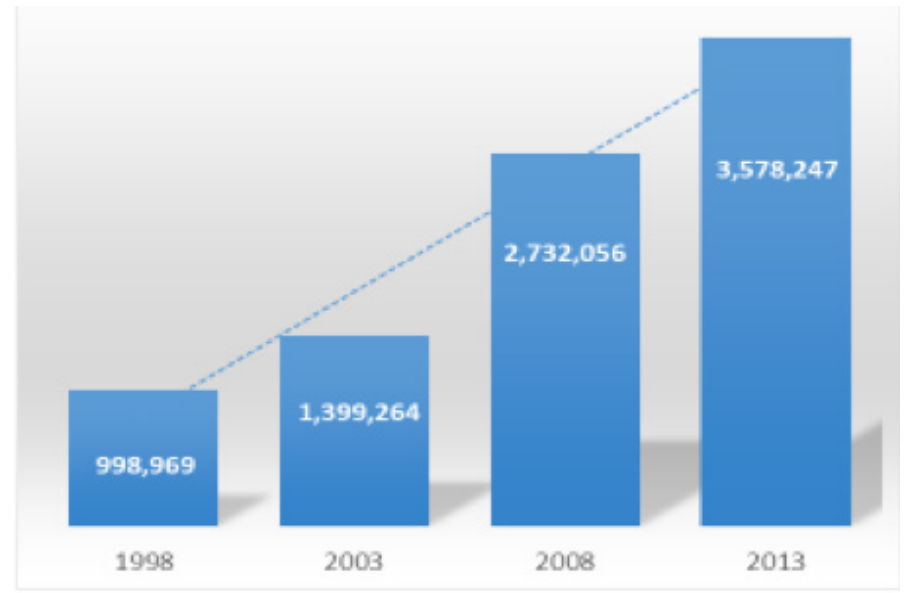

Fuente: elaboración propia con base en (Inegi, 2014, 2009, 2004). 
Cabe señalar que, según datos oficiales (Denue, 2017), en México existen 12813 establecimientos económicos con la figura de cooperativa, entre ellas se ubican cooperativas de producción, consumo, así como ahorro y préstamo, siendo las de producción las de mayor presencia nacional. Sin embargo, no se cuenta con datos desagregados que muestren la incidencia de las cooperativas de producción de servicios en actividades de subcontratación.

\subsection{Los aspectos legales}

Según la Ley General de Sociedades Cooperativas (2018) — publicada en 1994-, las cooperativas pueden ser integradas por personas físicas, las que comparten intereses comunes y practican principios de solidaridad, esfuerzo propio y ayuda mutua, además de que tienen el propósito de satisfacer necesidades individuales y colectivas (artículo 2..$^{\circ}$. En la ley se advierte la existencia de tres tipos de cooperativas: las de producción de bienes y/o servicios, de consumo de bienes y/o servicios, así como de ahorro y préstamo (artículo 21). En el artículo 27 de la Ley General de Sociedades Cooperativas (2018), se menciona que en las cooperativas de producción de bienes y/o servicios, los socios se unen para "trabajar en común en la producción de bienes y/o servicios, aportando su trabajo personal, físico o intelectual" (p. 6).

La característica típica de las cooperativas es que se dedican a la búsqueda del beneficio común en favor de los asociados, lo que se encuentra previsto en el artículo 28 de la Ley General de Sociedades Cooperativas (2018), donde además se prescribe que los rendimientos anuales se distribuirán entre los socios de acuerdo con el trabajo que ellos hubiesen aportado durante un año, para tal efecto se considerarán los factores relacionado con la calidad, tiempo, nivel técnico y escolar.

En la legislación cooperativa se prevé la posibilidad de que se simule constituirse en cooperativa sin serlo, de tal manera que en el artículo 10 indica la nulidad de las sociedades, como sigue:

Artículo 10. Las sociedades que simulen constituirse en sociedades cooperativas o usen indebidamente las denominaciones alusivas a las mismas, serán nulas de pleno derecho y estarán sujetas a las sanciones que establezcan las leyes respectivas. Se aplicará como legislación supletoria en materia de sociedades cooperativas, las disposiciones de la Ley General de Sociedades Mercantiles en lo que no se oponga a la naturaleza, organización y funcionamiento de aquéllas. (Ley General de Sociedades Cooperativas, 2018, p. 2) (Énfasis añadido por el autor)

En consecuencia, la creación de cooperativas simuladas también dio lugar a la existencia de la simulación de incorporación de socios de cooperativas, que se ha identificado como una forma de trabajo precario y que daría lugar a un supuesto de fraude laboral. Cabe señalar que la ley cooperativa en México no contiene causales de infracción o 
sanción para los supuestos de simulación, por lo que se debe atender a lo comprendido en las leyes supletorias.

Por tanto, se considera que la proliferación de prácticas indebidas a través de cooperativas emerge en México con la publicación de la legislación cooperativa en 1994 y las numerosas omisiones en sus disposiciones normativas, lo que dio lugar a diversos abusos. Dicha situación fue detectada tardíamente por el Servicio de Administración Tributaria y prevista como "practica indebida", a más de veinte años de la publicación de la legislación cooperativa.

Pero ¿cuál fue la problemática que derivó de la constitución de las cooperativas simuladas? A este respecto, debe decirse que además del tema tributario coexistía el asunto laboral con implicaciones nocivas para los trabajadores y amplios beneficios para el empleador.

Los escenarios que derivaron de las prácticas laborales mencionadas son explicados enseguida bajo dos aristas, la primera que se refiere a la omisión del impuesto sobre la renta y la segunda, a la elusión del pago de aportaciones de seguridad social (Seguro Social e Infonavit).

- Impuesto sobre la renta. Se detectó la evasión de retenciones a los trabajadores por los ingresos obtenidos, que eran declarados en cantidad menor a la realmente percibida, o bien, se les asignaban pagos como si se tratara de apoyos de previsión social.

- Aportaciones de seguridad social. Los trabajadores tienen derecho por ley, a servicios médicos que proporciona el Estado. Dicho servicio es cubierto a través de cuotas a cargo del patrón y del trabajador. Asimismo, el patrón está obligado a cubrir una cantidad por aportaciones a un fondo para la vivienda en beneficio de los trabajadores.

Las implicaciones en materia de seguridad social se describen enseguida:

- Seguro Social. Aunque el artículo 57 de la Ley General de Sociedades Cooperativas (2018) establece que los socios de cooperativas serán sujetos de aseguramiento de conformidad con la Ley del Seguro Social, en múltiples ocasiones son registrados con una remuneración menor a la realmente percibida o inclusive con un salario mínimo, lo que tiene como consecuencia que las prestaciones adicionales a los servicios médicos, sean muy bajas por haber sido cotizadas con un salario menor.

- Infonavit. En materia de Infonavit la legislación contempla que los obligados a pagar la aportación de seguridad social son los patrones, por tanto, por los asociados de las cooperativas no se está obligado a pagar dicha aportación, ya que se considera que el socio es en estricto sentido propietario de la cooperativa. 
Por lo mencionado, Lara y Rico (2007) detectaron diversas consecuencias en el tema de las aportaciones de seguridad social que se asocian con la relación laboral y que afectaron a los trabajadores reconocidos legalmente como socios de cooperativas de producción de servicios. Dichas consecuencias se enuncian a continuación:

1. Los falsos socios de cooperativas no tendrán derecho a percibir vacaciones, aguinaldo, prima vacacional, prima de antigüedad, y demás prestaciones sociales. Tampoco serán beneficiados con la participación en las utilidades de las empresas.

2. No tienen posibilidad de reclamar indemnizaciones por despido justificado o injustificado.

3. No podrán por ninguna causa integrar sindicatos de trabajadores.

4. No tendrán derecho a cotizar en el Infonavit.

5. El seguro de retiro y otras prestaciones que otorga el Seguro Social serán exiguas, por haber cotizado a un salario bajo.

Considerando el aporte de la OIT (2012) respecto al uso indebido de cooperativas en México, pueden identificarse arreglos contractuales y condiciones precarias en la relación generada, que se describen en la tabla 2.

Tabla 2. Contratos, precarización y prácticas indebidas de las cooperativas en México

Arreglos y condiciones

\section{Arreglo contractual:}

- Relación de trabajo encubierta.
Consecuencias que generan las cooperativas simuladas

- Constitución de una cooperativa de producción de servicios, con trabajadores que simulan ser socios de la misma.

\section{Condiciones precarias:}

- Salario bajo.

- Escasa protección frente al despido.

- Limitado acceso a la protección social.

- Posibilidad limitada o nula de los trabajadores de ejercer sus derechos en su trabajo.
- El salario bajo, implica cotizaciones de seguridad social reducidas (que significarían aportaciones monetarias a cargo del patrón).

- El despido no es viable para los socios de cooperativas, pero sí el retiro de la sociedad.

- No se tiene acceso al Infonavit y las prestaciones de seguridad social adicionales a los servicios médicos serán insignificantes.

- Es poco probable obtener resoluciones favorables ante los tribunales, debido a que el trabajador que simuló ser socio no podrá acreditar su calidad de trabajador.

Fuente: elaboración propia con base en OIT (2012).

Pese a que han surgido acciones por parte de las autoridades administrativas y se han dirimido asuntos en la Corte, esto no ha sido suficiente para detener la problemática del trabajo precario y el uso indiscriminado de figuras jurídicas (como las cooperativas). 
En el siguiente apartado se muestran los avances legislativos, así como las resoluciones administrativas y judiciales en el tema.

\subsubsection{Las leyes, criterios y resoluciones judiciales}

Considerando las problemáticas que emergieron en México desde los años noventa del siglo xx, derivado de las lagunas jurídicas o la ausencia de una legislación adecuada a los entonces novedosos esquemas de subcontratación, los legisladores realizaron algunas reformas a las leyes tributarias. Los aspectos que se analizarán se plasman cronológicamente en la figura 2.

Figura 2. Cronología legislativa sobre la subcontratación

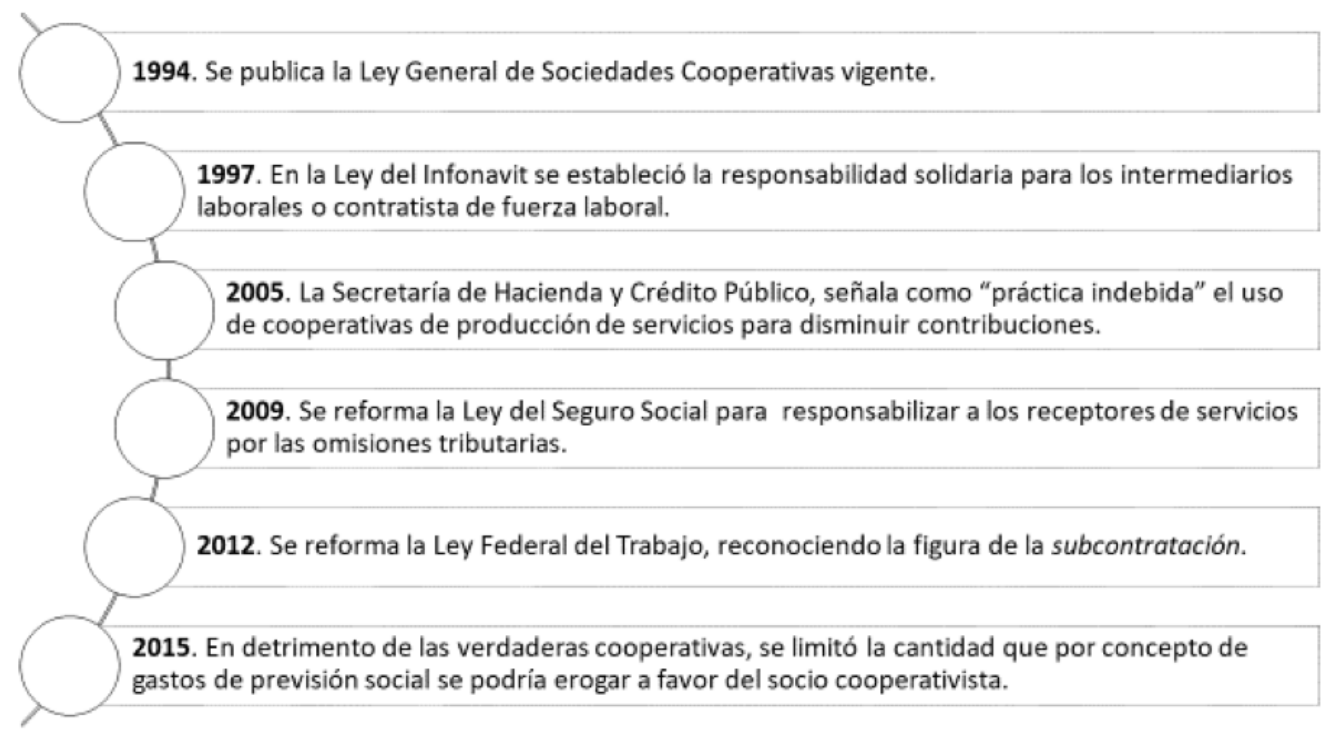

Fuente: elaboración propia con base en información de las normas citadas.

Las modificaciones se efectuaron a la Ley del Impuesto Sobre la Renta, a la Ley del Seguro Social y a la del Infonavit. También, la Secretaría de Hacienda y Crédito Público publicó criterios de tipo administrativo. Es importante mencionar que en 2012 se legisló en materia de subcontratación, introduciendo reformas en la Ley Federal del Trabajo que permitieron el uso abierto y legítimo de dicha práctica.

\subsubsection{El criterio administrativo}

En México, la Secretaría de Hacienda y Crédito Público (SHCP), posee la facultad de emitir criterios administrativos, con la finalidad de proporcionar opiniones a los contribuyentes, sobre actuaciones inadecuadas en el cálculo o pago de los impuestos. Sobre este particular, la autoridad advirtió de las "prácticas indebidas" que para evadir el 
Impuesto sobre la renta se venían realizando a través de diversas figuras jurídicas, entre ellas las cooperativas de producción. Tal como lo han dicho Lara y Rico (2007), la legislación cooperativa generó un espacio para la simulación, lo que luego fue motivo de acciones por parte de la SHCP. Así, a través de un criterio emitido el 14 de marzo de 2005 el Servicio de Administración Tributaria buscaba frenar la elusión fiscal que se perpetraba a través de cooperativas de producción de servicios, las cuales tenían la única finalidad de evitar el pago del impuesto sobre la renta por salarios y en general por la prestación de un servicio personal subordinado, así como de aplicar exenciones y deducciones sin cumplir con los requisitos y límites establecidos por la norma.

El criterio administrativo citado dio lugar a que la autoridad fiscal pusiera en marcha sus facultades de comprobación, dando inicio a diversas auditorías que concluyeron en los tribunales administrativos y judiciales. Posteriormente, se realizaron modificaciones a la Ley del Impuesto Sobre la Renta, limitando las deducciones por previsión social y clarificando algunos supuestos aplicables a las cooperativas a efectos de evitar la transgresión a través de la evasión fiscal.

\subsubsection{Los avances legislativos para limitar el uso indebido de las cooperativas}

Las acciones que surgen del Poder Legislativo con el objeto de frenar los esquemas simulados para crear cooperativas de producción de servicios en México se expresan a través de reformas a las leyes fiscales, que no han sido suficientes para frenar la simulación laboral y el uso indebido de cooperativas.

Algunos avances que se han derivado de la reforma a las leyes tributarias, se mencionan enseguida:

- Ley del Impuesto Sobre la Renta. Se limitó la cantidad que por concepto de gastos de previsión social se podría erogar a favor del socio cooperativista. Con dicha acción se puso un alto a tales pagos, por lo que en lo sucesivo el excedente pagado por este concepto sería objeto del gravamen a la renta (Ley del Impuesto Sobre la Renta, 2016).

- Ley del Seguro Social. Con la reforma a la Ley del Seguro Social publicada en 2009 se responsabilizó a los receptores de servicios, por la omisión del cumplimiento por parte de la empresa que otorgara servicios de subcontratación, en tal caso el beneficiario de los servicios asume las obligaciones que se deriven de la ley mencionada. Dicha disposición continúa vigente, tal como lo contempla la Ley del Seguro Social (2018). No obstante, debe mencionarse que, según Miranda (2016), solo una de cada nueve empresas dedicadas a la subcontratación se encuentra inscrita ante el Instituto Mexicano del Seguro Social. 
- Ley del Infonavit. En 1997 se reformó el artículo 29 bis de la Ley del Infonavit (2017), donde se estableció la responsabilidad solidaria para los contratantes o subcontratantes de fuerza laboral a través de empresas dedicadas a la tercerización, existiendo la obligación de que los patrones se inscriban en el Sistema de Responsabilidad Solidaria.

De este último punto, se extrae el texto legal como sigue:

Artículo 29 Bis. Cuando en la contratación de trabajadores para un patrón, a fin de que ejecuten trabajos o presten servicios para él, participe un intermediario laboral o contratista, cualquiera que sea la denominación que patrón e intermediarios asuman, ambos serán responsables solidarios entre sí y en relación con el trabajador, respecto del cumplimiento de las obligaciones contenidas en esta Ley. (Ley del Infonavit, 2017)

No obstante las reformas realizadas a las legislaciones mencionadas, hoy en día se siguen ubicando casos del uso indebido de las cooperativas y otras formas jurídicas que son utilizadas para evadir las cargas fiscales y laborales. Estas prácticas se han legitimado a partir del reconocimiento de la subcontratación como un régimen especial en la Ley Federal del Trabajo.

En este sentido, es relevante señalar que el 30 de noviembre de 2012 se incluyó una reforma a la Ley Federal del Trabajo, con la que se creó el régimen de subcontratación, legitimando plenamente tal figura jurídica, definiéndola y fijando sus características propias en el artículo 15-A, que enseguida se transcribe:

Artículo 15-A. El trabajo en régimen de subcontratación es aquel por medio del cual un patrón denominado contratista ejecuta obras o presta servicios con sus trabajadores bajo su dependencia, a favor de un contratante, persona física o moral, la cual fija las tareas del contratista y lo supervisa en el desarrollo de los servicios o la ejecución de las obras contratadas.

Este tipo de trabajo, deberá cumplir con las siguientes condiciones:

a) No podrá abarcar la totalidad de las actividades, iguales o similares en su totalidad, que se desarrollen en el centro de trabajo.

b) Deberá justificarse por su carácter especializado.

c) No podrá comprender tareas iguales o similares a las que realizan el resto de los trabajadores al servicio del contratante.

De no cumplirse con todas estas condiciones, el contratante se considerará patrón para todos los efectos de esta Ley, incluyendo las obligaciones en materia de seguridad social (Ley Federal del Trabajo, 2018). 
La incorporación de la reforma, en la Ley Federal del Trabajo tuvo como efecto la proliferación de contratos que avalaron el trabajo precario. De manera que dicha reforma y la legitimación de formas de trabajo basadas en la subcontratación han sido calificadas por Alcalde (2013, p. 1) como "uno de los fraudes sociales y laborales más crueles contra millones de mujeres y hombres que en nuestro país viven de su trabajo".

Desafortunadamente, aún no se han concretado acciones que aseguren una nueva reforma a la Ley Federal del Trabajo, que lleve a erradicar esta forma abusiva de contratación de la fuerza laboral.

\subsubsection{Las resoluciones judiciales}

Para conocer si se está ante una cooperativa auténtica o una cooperativa simulada, debe atenderse a lo establecido en la legislación de la materia (artículo 27 de la Ley General de Sociedades Cooperativas, 2018) y lo prescrito por la ScjN (2012), que determinó, a través de tribunales colegiados de circuito, las características distintivas de tales sociedades, enunciando las siguientes:

1. La vinculación recíproca de las partes para la realización de un fin común.

2. Las aportaciones que los socios realizan, ya sea a través de su trabajo, de su creatividad (ideas científicas, artísticas, culturales) o de su capital.

3. Las ganancias y las pérdidas deben entenderse como una igualdad entre las partes, lo que constituye a sus miembros en verdaderos socios, puesto que todos están llamados a beneficiarse de las primeras y a soportar las pérdidas. Tal como señala el punto 2 anterior, las aportaciones que se llevan a cabo pueden ser de distinto tipo, incluso en trabajo, por lo que el socio tendrá derecho a participar en los rendimientos y, en su caso, en las pérdidas (punto 3). En este sentido, la ScjN (1992) aclara, mediante una tesis en materia laboral, que los socios de cooperativas no serán en ningún caso trabajadores, señalando que "si la sociedad cooperativa acredita que el demandante tiene la calidad de socio de la misma, éste no puede alegar que además tenga el carácter de trabajador" (p. 245).

Tal resolución ha servido para limitar el acceso a un retiro laboral, ya que se desvincula la relación de socio cooperativista de la relación laboral a que se refiere la Ley Federal del Trabajo en México, lo que es correcto siempre y cuando la figura jurídica fuera utilizada de manera adecuada; pero se conoce que no es así, por lo que tal desvinculación de la relación laboral da lugar a eliminar los derechos que tendrían los falsos socios de cooperativas, ya que, como se ha mencionado, ellos no son considerados trabajadores, de manera que la cooperativa no está obligada a realizar aportaciones de seguridad social en materia de Infonavit, pero sí a realizar el aseguramiento en términos de la Ley del Seguro Social. 
Sobre el tema del Seguro Social e Infonavit se ha dictado jurisprudencia 171286 por la SCJN (2007, p. 555), aclarando la obligación que tiene la cooperativa de asegurar a sus socios, pero no así de cubrir las aportaciones al Infonavit. Existe una excepción que indica que la cooperativa deberá pagar las aportaciones de seguridad social cuando contrate trabajadores asalariados.

Como se ha visto, las falsas cooperativas han significado un instrumento eficaz para evitar las cargas laborales que derivan del salario, como es el pago de aportaciones de seguridad social, las prestaciones sociales, la participación de los trabajadores en las utilidades de las empresas, entre otros pagos derivados de la relación laboral. Sin embargo, más allá del notorio menoscabo de los derechos de los trabajadores, se encuentra la persistencia de las prácticas tendientes a disminuir los costos de las empresas, mediante resquicios u omisiones de tipo legal.

Las prácticas indebidas a través de cooperativas han llevado a la evasión fiscal. Tal como lo afirma Muñoz (2016), aproximadamente el $80 \%$ de las empresas dedicadas a la subcontratación - unas 1900 empresas - eluden sus obligaciones fiscales, lo que tiene como consecuencia la evasión de las aportaciones de seguridad social como el Seguro Social y la del Instituto del Fondo Nacional de la Vivienda para los Trabajadores (Infonavit) de unos dos millones de trabajadores. Los abusos laborales a que se ha hecho referencia se han venido dirimiendo en los tribunales sin mucho éxito para los trabajadores. En este sentido, a más de dos décadas de que el Fisco Federal (SHCP) hubiera detectado la existencia de cooperativas simuladas y denominara a tales prácticas de trabajo como indebidas, no se ha trascendido en avances legislativos efectivos en favor de los trabajadores y la consecuente erradicación del trabajo precario.

A este respecto, se ha reportado por el Inegi (2018) que existen muchos puestos de trabajo de tipo informal. No obstante, con la entrada en funciones del nuevo gobierno federal, se ha advertido que las prácticas de empresas dedicadas a la subcontratación están por terminar, ya que ha sido evidente que en el sexenio anterior, a pesar de que se crearon 2.69 millones de empleo, las cotizaciones al Seguro Social no incrementaron (Mendoza, 2018). Esto resulta ilógico, pues al existir subordinación y dependencia a un patrón se entendería la existencia de una relación laboral de la que derivarían prestaciones en favor de los trabajadores y su consecuente aseguramiento ante la entidad fiscal correspondiente, situación que no ocurre, lo que demuestra que aún falta mucho por hacer en México para erradicar las prácticas de trabajo precario a que se refiere la OIT y transitar hacia el trabajo decente. 


\section{Conclusiones}

El rol de la economía social y solidaria en la creación de nuevas e innovadoras formas de promover la ayuda mutua a través de organizaciones que comparten principios y valores basados en la solidaridad, el esfuerzo propio y la ayuda mutua, es importante para la generación de fuentes de trabajo y en general para el desarrollo de los países. Con la práctica de esta tendencia económica se busca la creación de redes de comercio y apoyo, nuevas formas de colaboración y de prácticas de trabajo, así como de otros mecanismos que fundamentalmente se centran en las personas, sus familias y las comunidades donde habitan, ofreciendo alternativas incluyentes y la certeza de que pueden generarse beneficios en favor de todos.

Algunas de las prácticas en el marco de la economía social y solidaria pueden ser observadas a través de una perspectiva que se aleja del trabajo tradicional, eliminando la relación asalariado-capitalista; algunos ejemplos son los bancos de tiempo, las cooperativas de trabajo asociado, entre otras que requieren de la fuerza laboral para el logro de fines comunes. Desgraciadamente, por todo el mundo se han replicado escenarios donde empresarios que justifican sus acciones en la competitividad y la búsqueda de su posicionamiento en el mercado han venido explorando esquemas flexibles de subcontratación que les permite reducir costos de operación y al mismo tiempo incrementar sus utilidades, lo que ha conducido a la simulación, a la evasión fiscal y a la precarización laboral.

Es por ello que en el contexto mexicano, desde la publicación de la Ley General de Sociedades Cooperativas en 1994 se han utilizado los esquemas señalados a través de la constitución de cooperativas de producción de servicios, sirviendo estas organizaciones como instrumentos para propiciar la evasión laboral e impositiva, lo que ha dado lugar a la proliferación de cooperativas simuladas y a la adhesión de falsos socios.

La situación mencionada ha traído consecuencias nocivas para los trabajadores y favorables para los empresarios. Entre las consecuencias para los trabajadores se encuentra el registro ante las autoridades, de salarios menores a los realmente acordados, por lo que las cotizaciones salariales de acuerdo con la Ley del Seguro Social son menores y en consecuencia las prestaciones también lo son. Paralelamente, los trabajadores no tendrán acceso a pagos por indemnización o retiro, por su condición de asociados de la cooperativa.

Dichos temas se ha dirimido ante la Corte y se han realizado modificaciones a las leyes impositivas y en materia de aportaciones de seguridad social; las medidas adoptadas por los poderes públicos no han sido suficientes para frenar la voracidad de los empresarios, los que todavía continúan utilizando esquemas de subcontratación a través de las cooperativas. 
Por lo mencionado, es innegable que la figura de las cooperativas sigue utilizándose para evitar cargas laborales a cargo del patrón y esto se debe a la legitimación de la subcontratación en la Ley Federal del Trabajo y a la ausencia de reformas eficientes que limiten o erradiquen las prácticas nocivas en materia cooperativa y de trabajo. Por todo ello, es impostergable que el Estado se comprometa e impuse reformas efectivas para el beneficio de los trabajadores, pero al mismo tiempo reconozca la importancia de la actividad empresarial en un mercado que demanda productos de calidad y a bajos costos.

\section{Referencias bibliográficas}

Abad, J., \& Abad, M. (2014). La economía social y solidaria como alternativa económica. Bienes comunes y democracia. Recerca, Revista de Pensament I Anàlisi. Núm. 15, pp. 55-75.

ACI (1995). Principios y valores cooperativos. Recuperado de https:/ / www.aciamericas. coop/Principios-y-Valores-Cooperativos-4456. [Consultado el 10 de enero de 2019].

ACI (2016). Hechos y cifras del cooperativismo en las Américas y el mundo. Recuperado de http://www.aciamericas.coop/Hechos-y-cifras-del-cooperativismo. [Consultado el 10 de enero de 2019].

Alcalde, J. A. (2013). El outsourcing en la reforma laboral. Periódico La fornada (sábado 27 de julio de 2013). Recuperado de https://www.jornada.com.mx/2013/07/27/ politica/013alpol [Consultado el 10 de marzo de 2019].

Coneval (2018). Estudio diagnóstico del derecho al trabajo 2018. Ciudad de México: Coneval. Recuperado de https://www.coneval.org.mx/Evaluacion/IEPSM/ Documents/Derechos_Sociales/Estudio_Diag_Trabajo_2018.pdf. [Consultado el 13 de enero de 2019].

Coraggio, J. L. (2007). "Una perspectiva alternativa para la economía social: De la economía popular a la economía del trabajo". En J. L. Coraggio (Coord.), La economía social desde la periferia. Contribuciones latinoamericanas. Buenos Aires: UNGS/Altamira.

De Lara L., M. (2017). Derecho al trabajo y trabajo precario en México. Dikê. Revista de investigación en Derecho, Criminología y Consultoría furídica / Benemérita Universidad Autónoma de Puebla, México, 165. ISSN: 1870-6924 / Año 11, No. 22, núm. 22, octubre de 2017- marzo de 2018, pp. 165-190.

Denue (2017). Directorio Nacional Estadístico de Unidades Económicas (Denue). Cooperativas. Recuperado de http://www.beta.inegi.org.mx/app/mapa/denue/. [Consultado el 10 de enero de 2019]. 
Revista CIFE / ISSN: 0124-3551 e-ISSN: 2248-4914 / Bogotá-Colombia / Vol. 21 N. 35 / julio-diciembre 2019 / pp. 81-104

Felber, C. (2012). La economía del bien común. Barcelona: Deusto.

Freítas, F. F. (2001). Terceirização no serviço público e cooperativas de trabalho. Consultoría Legislativa, Térreo Brasília, D.F. Recuperado de http:/ /www.observarh. org.br/nesp/projetos/desprec/pdfterc/faria_flavio.pdf. [Consultado el 13 de enero de 2019].

García, J. M. (2018). Falsas cooperativas, usos abusivos y derechos de los trabajadores. Análisis jurisprudencial y propuestas de actuación. Ciriec - España. Revista jurídica de economía social y cooperativa. ISSN 1577-4430, págs. 185-222.

Inegi (2004). Censos Económicos 2004. Desde https://www.inegi.org.mx/contenidos/ programas/ce/2004/doc/minimonografias/ct_personal_no_dependiente.pdf

Inegi (2009). Censos Económicos 2009. Desde https://www.inegi.org.mx/contenidos/ programas/ce/2009/doc/minimonografias/m_per_no_dep_razon_social.pdf

Inegi (2014). Censos Económicos 2009. Desde https://www.inegi.org.mx/contenidos/ programas/ce/2014/doc/frrdf_ce2014.pdf

Inegi (2018). Resultados de la Encuesta Nacional de Ocupación y Empleo (cifras durante el segundo trimestre de 2018). Recuperado de http:/ / www.beta.inegi.org.mx/contenidos/saladeprensa/boletines/2018/enoe_ie/enoe_ie2018_08.pdf. [Consultado el 10 de enero de 2019].

Lara, G. G., \& Rico, H. A. (2007). "Cooperativas de producción y outsourcing”. En M. Radrigan (Coord.), El rol de las cooperativas en un mundo globalizado. Canadá: Université de Sherbrooke.

Ley del Impuesto Sobre la Renta (2016). Camará de Diputados. H. Congreso de la Unión. Recuperado de: http://www.diputados.gob.mx/LeyesBiblio/pdf/LISR_301116. pdf. [Consultado el 15 de enero de 2019].

Ley del Infonavit (2017). Ley del Instituto del Fondo Nacional de la Vivienda para los Trabajadores. Cámara de Diputados. H. Congreso de la Unión, México. Recuperado de http://www.diputados.gob.mx/LeyesBiblio/pdf/86_240117.pdf. [Consultado el 15 de enero de 2019].

Ley del Seguro Social (2018). Cámara de Diputados. H. Congreso de la Unión, México. Recuperado de http://www.diputados.gob.mx/LeyesBiblio/pdf/92_220618.pdf. [Consultado el 15 de enero de 2019].

Ley Federal del Trabajo (2018). Cámara de Diputados. H. Congreso de la Unión, México. Recuperado de http://www.diputados.gob.mx/LeyesBiblio/pdf/125_220618.pdf [Consultado el 12 de marzo de 2019]. 
Ley General de Sociedades Cooperativas (2018). Cámara de Diputados. H. Congreso de la Unión, México. Recuperado de http://www.diputados.gob.mx/LeyesBiblio/ pdf/143_190118.pdf. [Consultado el 15 de en de 2019].

Martellini M. (2014). Los bancos del tiempo en España: combatiendo la recesión con la moneda social. CMG Senior Theses, 8(16).

Mendoza E., V. (2018). Inquietud empresarial por el fin del outsourcing. Forbes (5 de diciembre de 2018). Recuperado de https:/ /www.forbes.com.mx/inquietud-empresarial-por-el-fin-del-outsourcing/. [Consultado el 13 de marzo de 2019].

Merker, J. (2019). "Freelance isn't free". Co-working as a critical urban practice to cope with informality in creative labour markets. Urban Studies, 56(3), 526-547.

Miranda, J. C. (2016). Sin seguridad social, la mayoría de trabajadores en outsourcing, Periódico La fornada (Martes 16 de agosto de 2016). Recuperado de https://www.jornada.com.mx/2016/08/16/economia/022nleco [Consultado el 15 de marzo de 2019].

Muñoz R., P. (2016). Casi 80\% de las empresas de outsourcing eluden obligaciones fiscales, denuncian. Periódico La fornada (Jueves 4 de agosto de 2016, p. 17). Recuperado de https://www.jornada.com.mx/2016/08/04/politica/017n1pol. [Consultado el 8 de enero de 2019].

Neffa, J. C. (2010). "La transición desde los 'verdaderos empleos' al trabajo precario". En Enrique de la Garza Toledo y Julio César Neffa (Coords.), Trabajo, identidady acción colectiva. México: Plaza y Valdés Editores.

OIT (2012). Del trabajo precario al trabajo decente. Documento final del simposio de los trabajadores sobre políticas y reglamentación para luchar contra el empleo precario. Oficina Internacional del Trabajo, Oficina de Actividades para los Trabajadores (ACTRAV); Ginebra: OIT. Recuperado de https://www.ilo.org/wcmsp5/groups/ public/@ed_dialogue/@actrav/documents/meetingdocument/wcms_179789.pdf. [Consultado el 16 de febrero de 2019].

OIT (2015). Las cooperativas y los objetivos de desarrollo sostenible. Debate sobre el desarrollo después de 2015. Recuperado de http:/ / www.ilo.org/empent/Publications / WCMS_307228/lang--es/index.htm. [Consultado el 16 de febrero de 2019].

Pérez de Mendiguren, J., Etxezarreta, E., \& Guridi, L. (2008). ¿De qué hablamos cuando hablamos de economía social y solidaria? Concepto y nociones afines. XI Jornadas de Economía Crítica. Bilbao. 


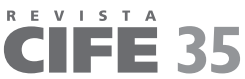

Revista CIFE / ISSN: 0124-3551 e-ISSN: 2248-4914 / Bogotá-Colombia / Vol. 21 N.o 35 / julio-diciembre 2019 / pp. 81-104

Popov, A., \& Rocholl, J. (2018). Do credit shocks affect labor demand? Evidence for employment and wages during the financial crisis. Fournal of Financial Intermediation, $36,16-27$.

Rojas Ch., A. (2004). La Intermediación Laboral. Revista de Derecho. Universidad del Norte, núm. 22, pp. 167-210.

Roy, N., \& Verdun. A. (2019). Bangladeshi Migrants of Italy and Their Precarity. Soc. Sci. 2019, 8, 123.

SCJN (1992). Cooperativa de producción, sus socios no deben ser considerados trabajadores de la misma. Octava Época. Registro 217911. Tribunales Colegiados de Circuito. Semanario Judicial de la Federación. Tomo X, p. 245.

SGJN (2007). Sociedades cooperativas. Deben cubrir al Infonavit las aportaciones de sus trabajadores, no así de sus socios cooperativistas. Novena Época. Registro 171286. Segunda Sala (Jurisprudencia). Semanario Fudicial de la Federación y su Gaceta. Tomo XXVI, Septiembre de 2007. Tesis 2a. /J. 178/2007, p. 555.

SCJN (2012). Sociedad cooperativa. Sus notas distintivas y definición. Décima Época. Registro 159892. Tribunales Colegiados de Circuito. Semanario fudicial de la Federación y su Gaceta. Libro XV, Diciembre de 2012, Tomo 2. Tesis I.3o.C.1037 C (9a.), p. 1566.

Stiglitz, J. (2015). La gran brecha. México: Taurus.

Tirole, J. (2017). La economía de bien común. México: Taurus. 